\title{
Wheat Germ Oil
}

National Cancer Institute

\section{Source}

National Cancer Institute. Wheat Germ Oil. NCI Thesaurus. Code C107372.

The oil extracted from the germ of the wheat kernel. Wheat germ oil can be used as a source of vitamin $E$ and for the treatment of skin conditions. 